\title{
Android-Based Geographic Information System in Mapping Location of Health Facilities and Infrastructure in Merauke District
}

\author{
Stanly Hence Dolfi Loppies ${ }^{1}$ \\ Information Systems Department \\ Universitas Musamus \\ Merauke, Indonesia \\ ${ }^{1}$ stanly@unmus.ac.id
}

\author{
Hermin Agian Kaba², Izak Habel Wayangkau \\ Informatics Engineering Department \\ Universitas Musamus \\ Merauke, Indonesia \\ ${ }^{2}$ herminagiankaba@gmail.com, ${ }^{3}$ izak@unmus.ac.id
}

\begin{abstract}
Information needs by the community of Merauke Regency in this era are becoming more complex and diverse. The community needs a quick and easy access to obtain the information needed, one of them is by using a smartphone that is now owned by almost all people in the city of Merauke from various backgrounds. Health facilities and infrastructure in Merauke Regency are under the Health Office of Merauke Regency, with a total of 20 Drugstores, 4 Hospitals, 6 Community Health Centers, 10 Clinics and Polyclinics and 2 Dentists that has been registered in Merauke District. But unfortunately, the map of the regency and district of Merauke which are listed on the Google Map cannot display all of the existing health facilities and infrastructure. The methods of data collection used were literature studies, interviews and observations. The method of the test was the test for the application's interface functionality and questionnaire. The results obtained was in the form of Health Facilities and Infrastructure in Merauke that could be well mapped with complete information on Android.
\end{abstract}

Keywords-Map; Health Infrastructure; Android

\section{INTRODUCTION}

Information needs by the community of Merauke Regency in this era are becoming more complex and diverse. The community needs a quick and easy access to obtain the information needed, one of them is by using a smartphone that is now owned by almost all people in the city of Merauke from various backgrounds. [1]

The data of health facilities and infrastructure that is obtained from the Health Office of Merauke Regency records that there are 42 health facilities and infrastructure with categories: 20 drugstores, 4 hospitals, 6 community health centers, 10 clinics and polyclinics and 2 dentists in the Merauke District. The Health Office has the duty to control all of the health facilities in a region from hospitals, community health centers, community health sub-centers, drugstores, independent practice of midwifery and others. But until now, the Health Office of Merauke Regency does not have an information system facility that can be used by the community to obtain information regarding the location of the health facilities and infrastructure.
Google map is one of the facilities provided by Google (http://maps.google.com/) to find information of a location [2] that has a function as a geographic data and information search engine that is currently synchronized with various Androidbased and web-based searching applications. [3] Until now, the updated map of the Regency and District of Merauke in the Google Map is not complete in displaying information about the location of health facilities in Merauke Regency, it is only covering data of large hospital with lack of detail information.

Geographic Information System is a system that can support spatial decision making and able to integrate descriptions of a location with the characteristics of phenomena found in that location. A complete GIS includes the methodology and technology needed, such as spatial data, hardware, software and organizational structure. [4]

Cartography is a study of how to create maps that are in accordance with aesthetics and the art of presentation so that they are easy to read and understand. [5] Sign on a map such as symbols, markers, colors will make it easier for users to find information that they want to obtain. [4]

\section{THEORETICAL FRAMEWORK}

\section{A. Geographic Information System}

Geographic information system is a combination of three main elements: system, information and geography. By looking at the main elements, it is clear that GIS is one of the information systems with the addition of "geographical" elements or GIS is a system that emphasizes the element "geographical information". The term "geographic" is part of spatial. The use of the word "geographic" contains a description on an issue about the earth: the surface of two or three dimensions. The term "geographical information" contains an understanding of information about places located on the surface of the earth, knowledge of the position where an object is located on the surface of the earth and information about the attributes contained on the surface of the earth whose position is given or known [6]. 


\section{B. Cartography}

Cartography is the study of how to create maps that are in accordance with aesthetics and the art of presentation so that they are easy to read and understand. Cartography is also a technique that is fundamentally associated with the activity of minimizing the spatial area of a part or whole region so that it can be used for communication purposes. The duty of cartography is to move physical reality (geographic phenomena) into a map, and not just a reduction of the geographic phenomena. In the process of transferring physical reality or this geographic abstraction is called cartographic abstraction. There are four things that need to be fulfilled in the cartographic abstraction: selection, classification, simplification and symbolization [5].

\section{Google Map}

Google Maps (formerly known as Google Local) is a free web-based map server, application and technology provided by Google. Google Maps is a technology that becomes the background of other technological developments, such as Google Ride Finder. Google Maps can also be used as an indication to complete the third party's websites that use the Google Maps API (Application Programming Interface). Google Maps API is an application feature issued by Google to facilitate users who want to integrate google maps into their websites by displaying their own data points, by adding an API key as an identifier. Google Maps is used for various purposes such as planning routes and places to consider business locations for countries such as Australia, Canada, Japan, New Zealand, Western European countries and the United States.

When observed from its shape, Google Maps is a map that can be navigated using a mouse like Google Earth. The map can also be enlarged or reduced.

There are three visual models that can be selected in the Google Maps, those are as follows:

1. Map (road map)

2. Satellite (high resolution Satellite imagery and aerial photography)

3. Hybrid (high resolution road map covering Satellite imagery and aerial photography)

GIS maps used by Google Maps are provided by external parties, such as Tele Atlas and NAVTEQ. The high resolution pictures are provided by Digital Globe and its satellite called QuickBird. Other pictures are obtained from government sources.

Maps of Regency and City of Merauke that are obtained using Google Maps directly can be seen in Figure 1 and Figure 2 below.

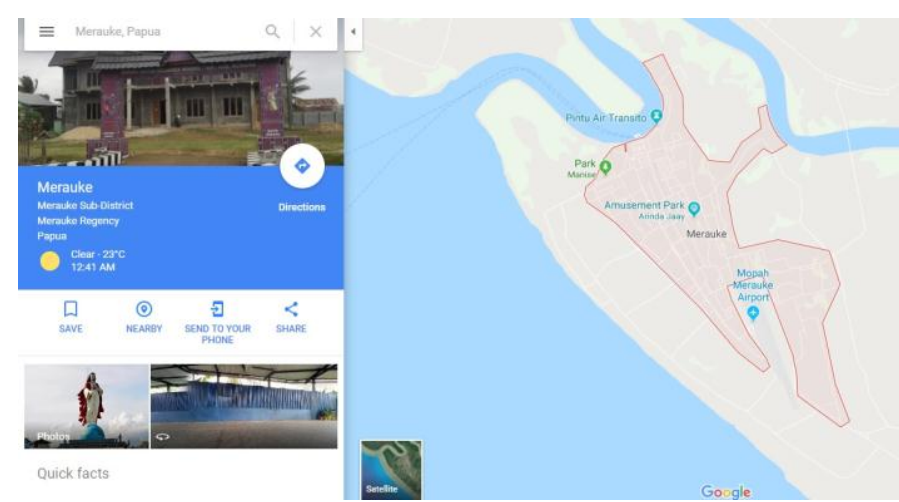

Fig. 1. Google Maps of Merauke Regency

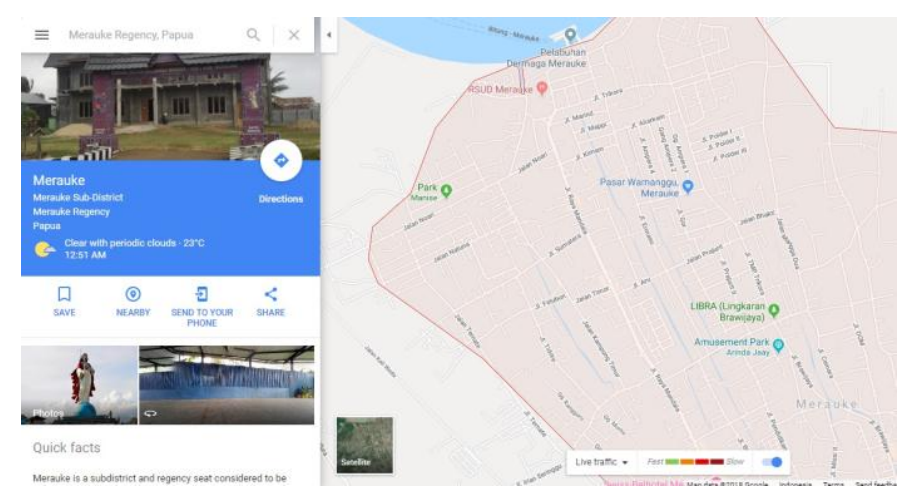

Fig. 2. Google Maps of District/City of Merauke

\section{Android}

Android is a Linux-based operating system designed on a mobile device (smartphone or tablet computer). The main advantage of Android is the integrated application approach, where the developer only concentrates on the application, the application can run on several different devices as long as it is still powered by Android (the developer does not need to consider the needs of the type of device).[7] In general, the Android operating system is divided into five levels:

\section{- Linux kernel}

Linux kernel is the basic kernel of Android. This level contains all low-level device drivers for hardware components of Android devices.

\section{- Libraries}

Contains all program codes that provide the main services of the Android operating system. For example, the SQLite library provides database support so that Android applications can use it to store the data. WebKit Library provides web browser functions and others.

- Android Runtime

Its position is equivalent to libraries, Android Runtime provides a collection of core libraries that can be activated by developers to write android application code with the Java programming language. Dalvik Virtual Machine is active every time the Android application proceeds (the Android application is compiled into Dalvik Executable). Dalvik is a quasi-engine 
designed specifically for Android that can optimize the battery power of mobile devices with limited memory and CPU.

- Application Framework

It is a collection of built-in classes that are embedded with the Android operating system so that the developers can use it for applications that are being built.

- Application

It is the top level in the level of Android architecture. At this level, the user performs activities on the Android interface, such as operating: Phone, Contact, Browse and other applications that can be downloaded and installed from Market Android (Playstore).

Android architecture if described completely can be seen in Figure 3. below

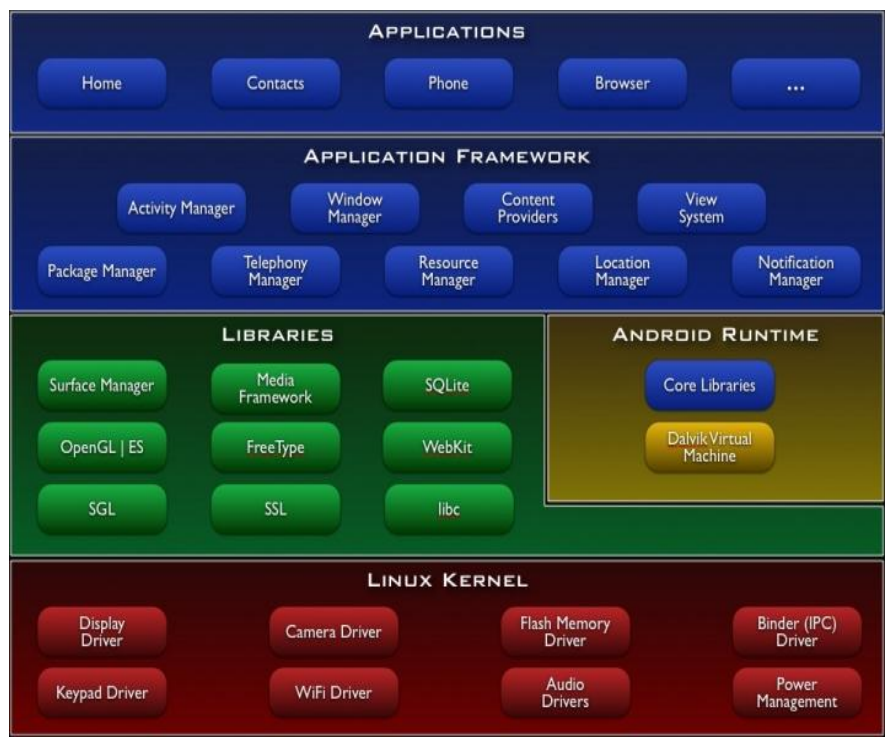

Fig. 3. Android Architecture

\section{METhodology AND SYSTEM DESIGN}

Geographic Information System of the Health Facilities and Infrastructure Mapping in Merauke Regency is built based on the analysis of the need obtained from the data that has been collected through interviews and observations so that a general system design is drawn up in the flowchart and context diagram.

\section{A. Data Sources}

The data obtained in this study came from the Health Office of Merauke Regency and the literature studies from various sources.

Health facilities and infrastructure data obtained from the Health Office recorded that there are 42 health facilities and infrastructure with categories: 20 drugstores, 4 hospitals, 6 community health centers, 10 clinics and polyclinics and 2 dentists. To complete the required data, the writers conducted a survey in the field to retrieve the coordinate data on each of the Facilities and Infrastructure in the Merauke District.

Health development activities carried out in Merauke Regency also tried to improve the health status of the community in this area through various health service programs and activities, alone or with other sectors or even in partnership with the community, as stated in the Vision, Mission, Development Goals and Strategies of the Regent of Merauke Regency. The main strategy is that health services must reach the community in 168 administrative villages/ villages at any time if needed beside the strengthening the community empowerment through the Village Program/ Desa Siaga, Revitalizing the Integrated Health Service Post and Reforming the Community Health Center in organizing promotive and preventive health services. The aim is to reduce the maternal and infant mortality, reduce the prevalence of malnutrition and increase the life expectancy of the community of Merauke. Healthy Indonesia should start from a healthy village so that it creates a Healthy District/City, then a Healthy Regency and finally a Healthy Country.

The data obtained is then processed and inputted into the system so that it can be used as a completeness in making the Android-based Geographic Information System and Health Infrastructure Information System Application in Merauke Regency.

\section{B. Flowchart Sistem}

The system flowchart in Figure 4. below illustrates the flow of the system usage process.

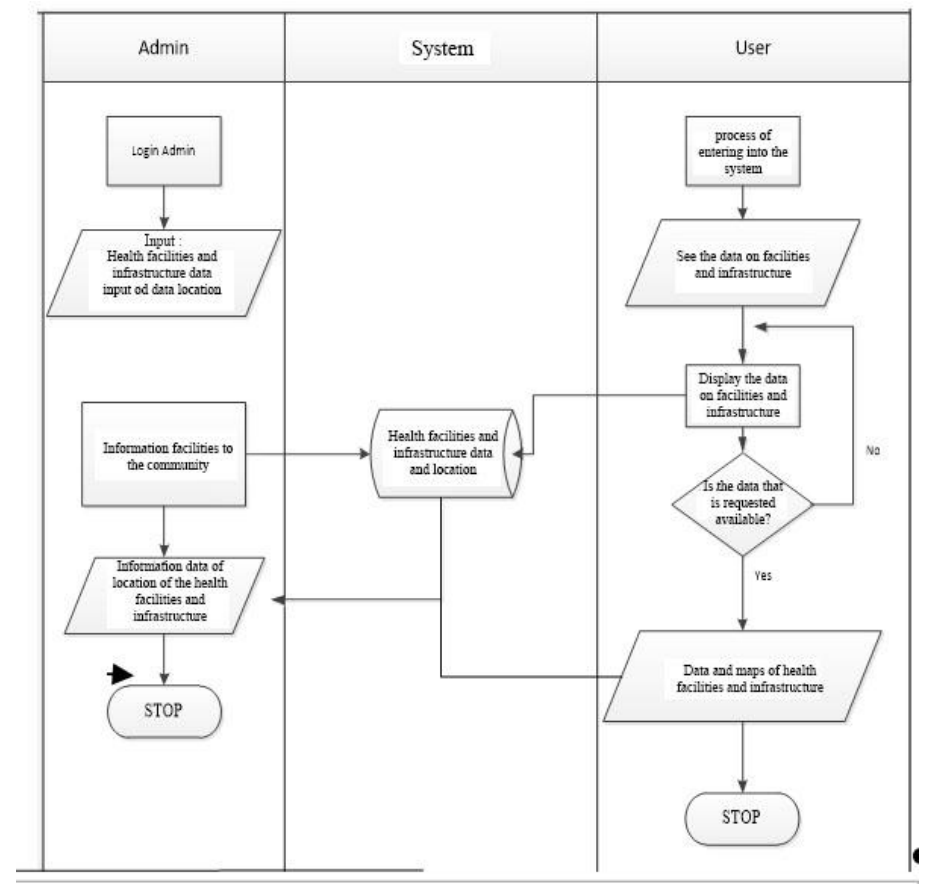

Fig. 4. System Flowchart

On the system flowchart above, it can be explained that the user of this system is admin and user. In this case the admin is an employee of the Health Office of Merauke Regency, while the user is the community. The admin is responsible for registering the facilities and infrastructure that previously have been registered and those that have just registered. After it was registered, the application can display a map of the location of the facilities and infrastructure on the people's smartphone. 
People only need to open the application that has been installed on smartphones and

C. Database table relations

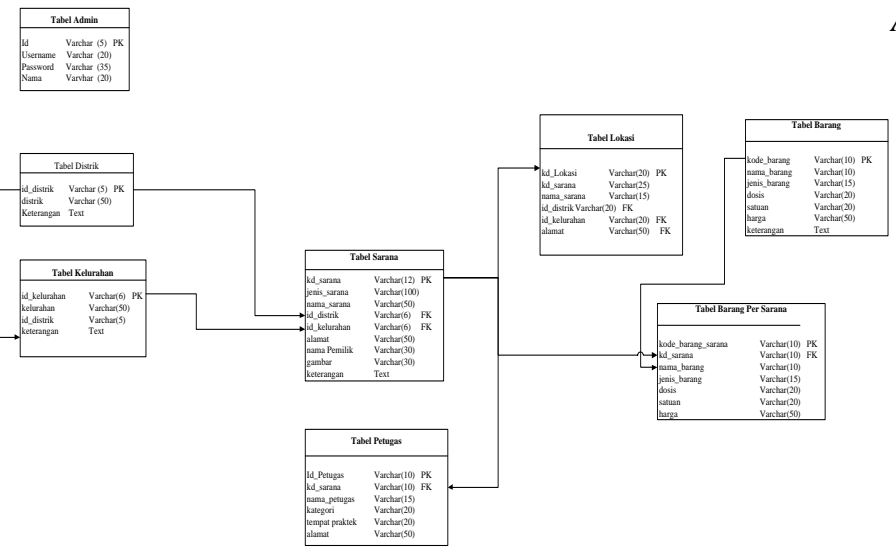

Fig. 5. Database Table Relations

\section{Context Diagram}

Context diagram is a general description of the system or application and its interaction with the system or applications users. The context diagram of the Android-based application of health facilities and infrastructure of the city of Merauke can be seen in Figure 6. below.

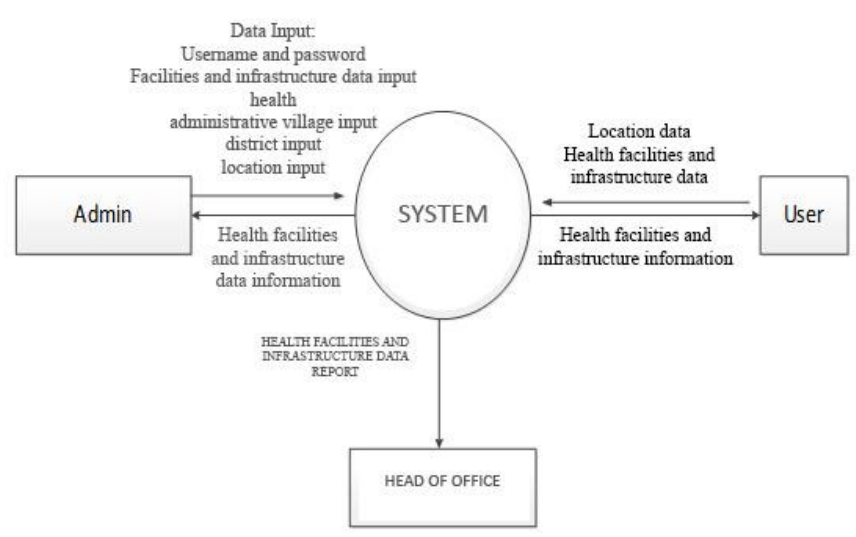

Fig. 6. Context Diagram

The explanation of context diagram above is that this system or application can be accessed by three users, namely admin, user, and head of office. Admin has the duty to enter or register the existing health facilities and infrastructure in Merauke in accordance with the health facility or infrastructure registration report that has been registered on the Health Office of Merauke Regency. Users or the community use a system or application to find the desired data on facilities and infrastructure. The head of office can receive data reports on health facilities and infrastructure that have been registered in Merauke Regency through a system or application.

\section{RESULTS AND DISCUSSION}

A. Test Results

1) Application interface functionality

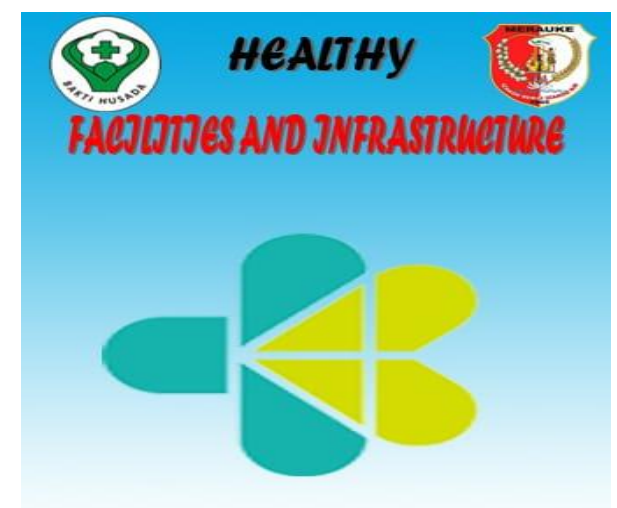

Fig. 7. Splash Screen of the Application

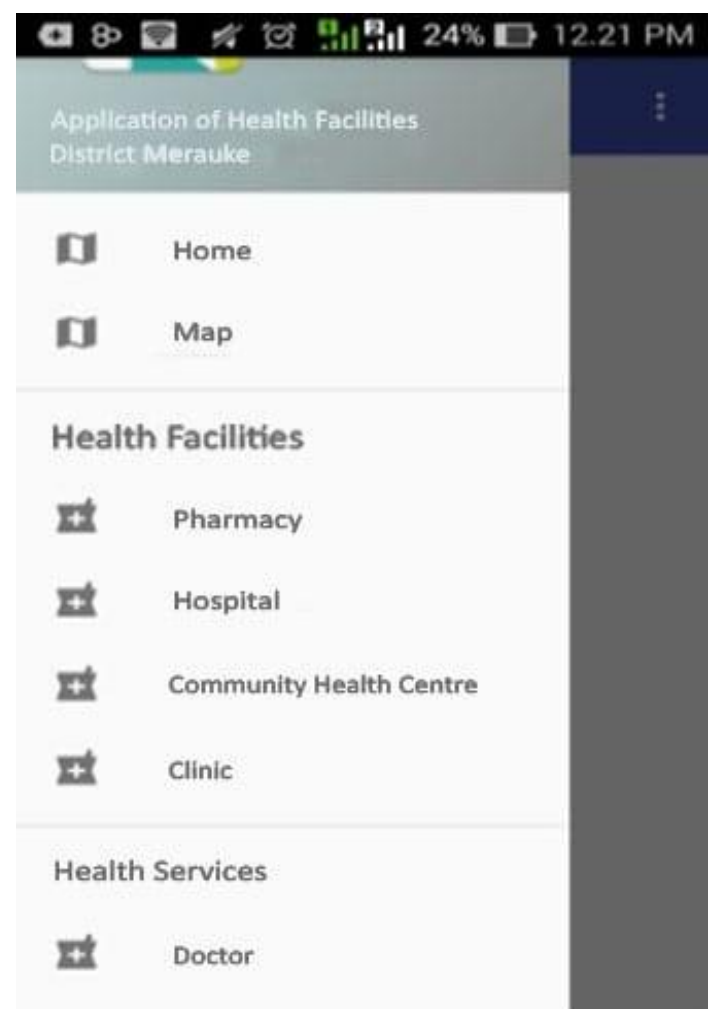

Fig. 8. Main Menu of the Application 


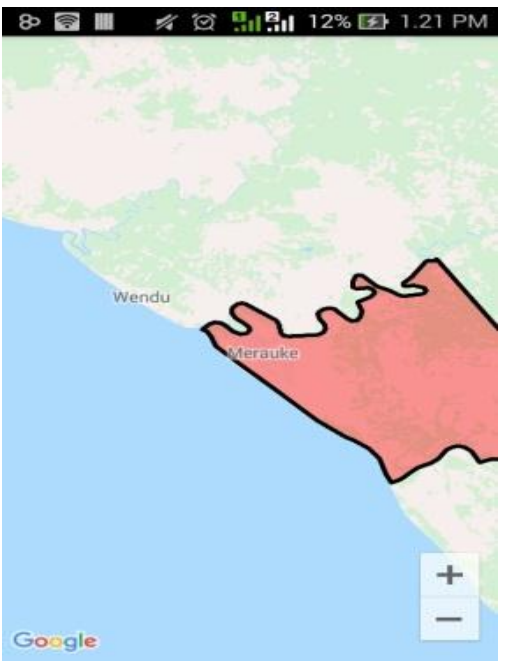

Fig. 9. Merauke City Area

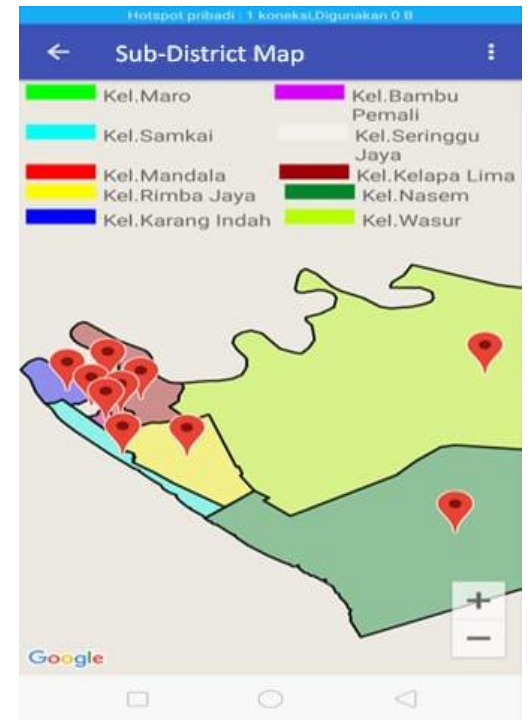

Fig. 10. Map of the Administrative Village in Merauke

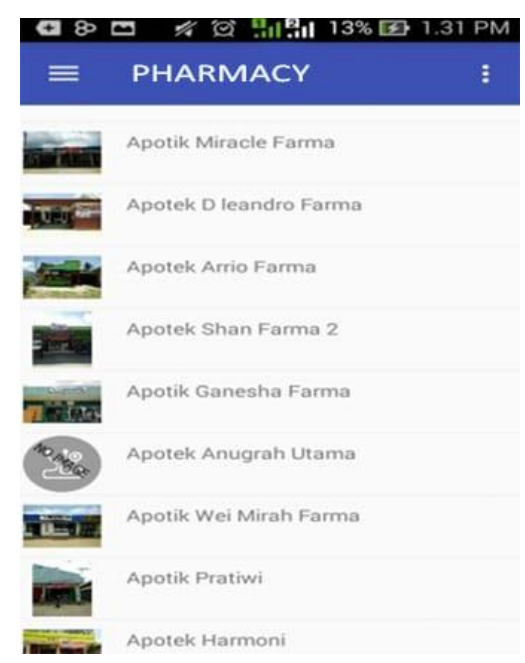

Fig. 11. Examples of Drugstore Facilities in Merauke District

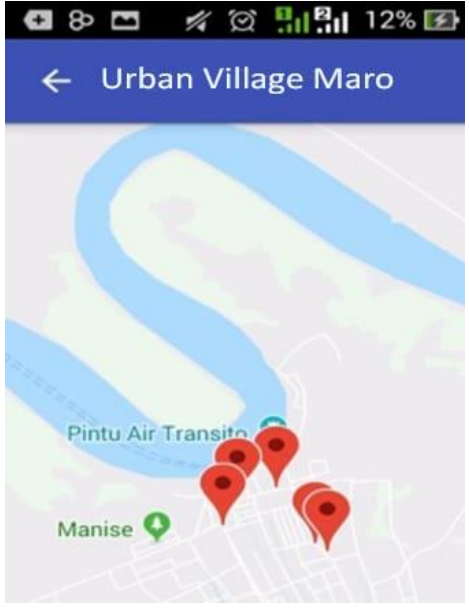

Fig. 12. Facilities in one of the administrative villages

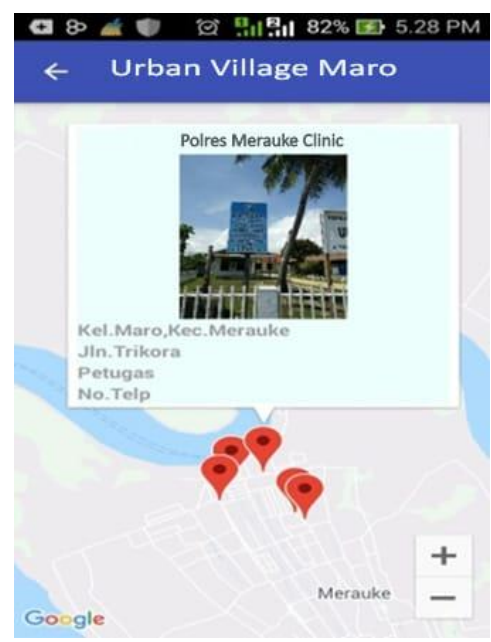

Fig. 13. Information $\mathrm{f}$ selected according to the marker

\section{2) Questionnaire}

The test with Questionnaire aims to test the system components that have been previously designed and to ensure that each element of the system is functioning as expected. The test of this program was carried out by 20 users per administrative village from 10 administrative villages in the city of Merauke and the head of the Health Office of the Merauke Regency. The clients ran applications to test the system functionality and used GPS (Global Positioning System) to ensure the accuracy of the location of the health facilities and infrastructure. The results of this test were done by filling out a questionnaire as the response to the tests that have been carried out. The record of the questionnaire results can be seen in Figure 14. 


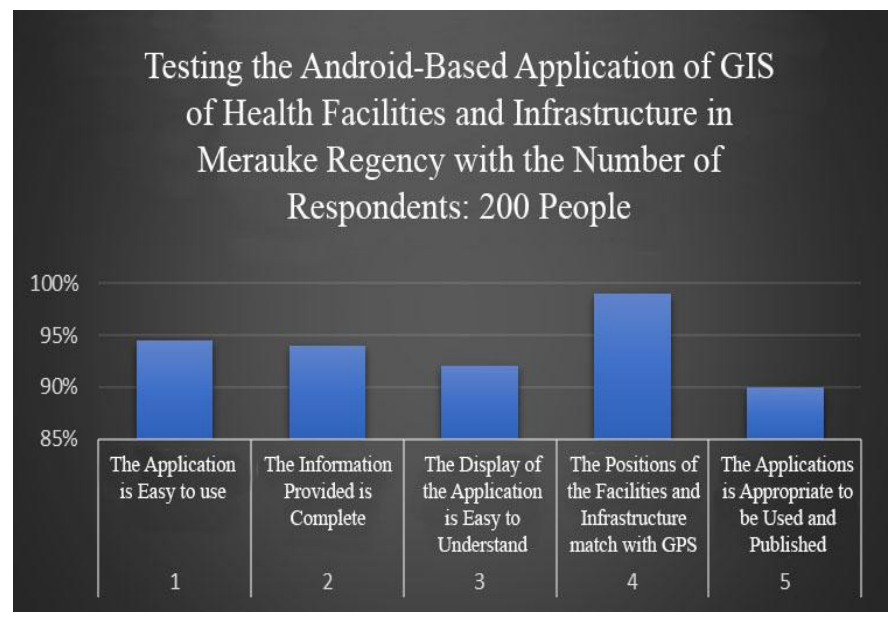

Fig. 14. Record of questionnaire results

\section{B. DISCUSSION}

Based on the results of the tests that have been carried out on the application and through the distribution of questionnaires, it was found that the functionality of the system has been able to be operated and it is functioning properly. The compatibility of the information and the accuracy of the coordinates displayed on the application if it is matched with the GPS (Global Positioning System) was also compatible. This was certainly very good for the users of the application in searching and finding locations and information on health facilities and infrastructure that they want to find.

\section{CONCLUSION}

Based on the results of the system testing that has been carried out, the conclusions that can be drawn is that Health Facilities and Infrastructure in Merauke City has been mapped well with complete information on Android.

\section{REFERENCES}

[1] L. Penelitian and P. Masyarakat, "Prosiding," in Konferensi Nasional Sistem Informasi, 2016, p. 212.

[2] M.N.K. Boulos, "Web GIS in practice III: Creating a simple interactive map of England's Strategic Health Authorities using Google Maps API, Google Earth KML, and MSN Virtual Earth Map Control,” Int. J. Health Geogr., vol. 4, pp. 1-8, 2005.

[3] E.T.P.M. Sholeh, C. Iswayudi, "E-Museum: Museum Information in Yogyakarta Based on Location Based System," Pros. Semin. Nas. Apl. Sains Teknol. 2014 Yogyakarta, 15 Novemb. 2014 ISSN 1979-911X, no. November, pp. 51-58, 2014.

[4] N. Zulkarnain, "Cartographic Analysis of Map of Scale 1: 5000 Village Based on Head of BIG Regulations Number 3 of 2016 (Case Study: Beran Village, Ngawi Regency)," vol. 6, no. 2, p. 121, 2017.

[5] O.M. Sukoco, "WIIAYAH PLANNING CARTOGRAPHY," no. 08, pp. 39-49, 1991.

[6] R. Muryamto et al., "Making maps and geospatial information systems of agricultural land in Sentolo sub-district, Kulonprogo district, Yogyakarta," no. 10, pp. 278-287, 2014.

[7] W.M. Lee, Beginning Android ${ }^{\mathrm{TM}}$ Application Development, 2011. 